\title{
A new species of Propimelodus Lundberg \& Parisi, 2002 (Siluriformes: Pimelodidae) from rio Araguaia, Mato Grosso, Brazil
}

\author{
Marcelo S. Rocha, Renildo R. de Oliveira and Lúcia H. Rapp Py-Daniel
}

\begin{abstract}
A new species of Propimelodus from the middle course of the rio Araguaia is described. Propimelodus araguayae, new species, can be distinguished from its congeners in having a conspicuous black dot on the base of the dorsal-fin rays (vs. a different pattern), large eyes (29.7-34.8\% of head length and $62.7-74.7 \%$ of snout length $v$ s. $14.5-21.1 \%$ and $31-44 \%$ in P. caesius and $9.5-19.7 \%$ and $17-38 \%$ in P. eigenmanni), anal-fin lobe present ( $v s$. absent), premaxillary bone with three irregular rows of teeth (vs. 4-5 in P. caesius and 5-8 in P. eigenmanni), tip of anterior lateral process of basipterygium at the same level as the tip of the anterior medial process ( $v s$. anterior lateral process extending beyond the tip of the anterior medial process), total number of vertebrae (43-44 vs. 47-48 in P. caesius and 45-46 in P. eigenmanni) and total number of gill rakers (28-33vs. 20-23 in P. caesius and 19-20 in P. eigenmanni). This new species is possibly endemic to the middle course of the rio Araguaia.
\end{abstract}

Uma nova espécie de Propimelodus do trecho médio do rio Araguaia é descrita. Propimelodus araguayae, nova espécie, pode ser distinguida de suas congêneres pela presença de uma conspícua mancha preta na base dos raios da nadadeira dorsal ( $v S$. um padrão distinto), olhos grandes (29,7-34,8\% do comprimento da cabeça e 62,7-74,7\% do comprimento do focinho vs. 14,5$21,1 \%$ e $31-44 \%$ em P. caesius e 9,5-19,7\% e 17-38\% em P. eigenmanni), presença de um lobo na nadadeira anal ( $v$ s. ausente), premaxilar com três fileiras irregulares de dentes (vs. 4-5 em P. caesius e 5-8 em P. eigenmanni), extremidade do processo medial anterior do basipterigio na mesma transversal que passa na extremidade do processo lateral anterior ( $v s$. extremidade do processo medial anterior do basipterigio não atingindo a transversal que passa pela extremidade do processo lateral anterior), menor número total de vértebras (43-44 vs. 47-48 em P. caesius e 45-46 em P. eigenmanni) e maior número de rastros branquiais no primeiro arco (28-33 vs. 20-23 em P. caesius e 19-20 em P. eigenmanni). Esta nova espécie é possivelmente endêmica ao curso médio do rio Araguaia.

Key words: Catfish, Systematics, Propimelodus araguayae, Propimelodus eigenmanni, Propimelodus caesius.

\section{Introduction}

The genus Propimelodus was proposed by Lundberg \& Parisi (2002) for Pimelodus eigenmanni Van der Stigchel (1946), a species distinct of Pimelodidae with very long adipose fin and an unsupported relationship with Pimelodus maculatus (type species of the genus) and other Pimelodus species (Parisi et al., 2006). A synapomorphy of the genus Propimelodus is the hypertrophied structure of the palatine and ectopterygoid bones (Lundberg \& Parisi, 2002).

Recently, a second species, Propimelodus caesius, was described and distinguished from P. eigenmanni by its larger eye, circular patch of small teeth on the metapterygoid, total vertebral count and coloration (Parisi et al., 2006). Species belonging to Propimelodus are currently known from the Amazon River mainstem in Brazil and Peru and lower reaches of its major tributaries (Parisi et al., 2006). Propimelodus caesius has been mainly found in turbid and black waters but has never been captured in the clear-water rio Tapajós, or in relatively clear-water lakes (such as the lakes along rio Tefé and rio Coari) (Parisi et al., 2006).

In this work, we describe a new species of Propimelodus from the middle rio Araguaia, Mato Grosso State, in Brazil, a clear-water river that drains the Brazilian shield.

\section{Material and Methods}

Counts and measurements follow Lundberg \& McDade (1986) and Lundberg \& Parisi (2002). The measurements were made on the left side of the specimens with a digital caliper to the nearest $0.1 \mathrm{~mm}$. Additional measurements include: (1) preadipose length measured from the adipose-fin origin to snout tip; (2) prepelvic length measured from the insertion of the outer pelvic-fin ray to snout tip, and (3) posterior nostrileye distance measured from the posterior margin of the posterior nostril to the anterior margin of the orbit.

Programa de Coleções e Acervos Científicos, Instituto Nacional de Pesquisas da Amazônia, Caixa Postal 478, 69011-970 Manaus, AM, Brazil.msrocha@inpa.gov.br, renildo@inpa.gov.br, rapp@inpa.gov.br 
Measurements related to the head are presented as percentages of head length and those related to the body, including head length, are presented as percentages of standard length. Measurements of eye diameter (horizontal) are presented as percentages of snout length.

SEM (scanning electron micrographs) pictures were taken from cleared and stained dissected specimens.

Osteological characters were examined from specimens cleared and stained (cs) according to Potthoff (1984). Vertebral counts include six elements in the Weberian complex; the first caudal vertebra is that immediately posterior to the visceral cavity; the compound caudal vertebra (PU1+U1) is counted as one. Counts of gill rakers include all rudiments and were made on the first branchial arch.

\section{Results}

\section{Propimelodus araguayae, new species} Figs. 1, 2a

Holotype. INPA 26119, $127.1 \mathrm{~mm}$ SL, Brazil, Mato Grosso, Barra do Garças, rio Araguaia, 1550'15”S 51 $58^{\prime} 43$ ”'W, 15 Jun 2006, Humberto P. Rego.

Paratypes. INPA 26120 (8, 124.6-131.9 mm SL) (2 cs, $121.5 \mathrm{~mm} \mathrm{SL})$, collected with the holotype. INPA 26121 (5, 114.1-137 mm SL) (1 cs, $115 \mathrm{~mm}$ SL), Brazil, Mato Grosso, Barra do Garças, rio Araguaia, 1550'15”S 5158'43”W, 12 May 1992, Paulo C. Venere et al.

Diagnosis. Propimelodus araguayae can be distinguished from its congeners by: a conspicuous black dot on the dorsal-fin (vs. absent) (Figs. 1-2); large eyes, 29.7-34.8\% of head length and $62.7-74.7 \%$ of snout length ( $v s .14 .5-21.1 \%$ of head length and $31-44 \%$ of snout length in $P$. caesius and $9.5-19.7 \%$ of head length and $17-38 \%$ of snout length in P. eigenmanni); anal-fin lobe present ( $v s$. absent); tip of anterior medial process of basipterygium at the same level of the tip of the anterior lateral process ( $v s$. anterior lateral process extending beyond the tip of the anterior medial process); premaxillary bone with three irregular rows of teeth (vs. 4-5 in P. caesius and 5-8 in $P$. eigenmanni); total vertebrae count 43-44 (vs. 47-48 in P. caesius and 45-46 in P. eigenmanni); gill rakers on first branchial arch 28-33 (vs. 20-23 in P. caesius and 19-20 in P. eigenmanni).

Description. Morphometric data presented in Table 1. Maximum size $136 \mathrm{~mm}$ SL. Head profile convex from tip of the snout to posterior margin of orbit, then gently concave to nuchal plate. Dorsum profile almost horizontal from dorsal spine to adipose fin origin. From this point, profile falls in straight line and becomes slightly concave at end of adipose fin until caudal-fin base. Ventral profile gently inclined from mouth to pectoral-fin origin, convex along abdomen, straight from pelvic to anal-fin origin, then rising in a concave curve to caudal-fin base.

Dorsum of head covered with thin skin. Anterior nostril located immediately anterior to maxillary barbel base; anterior nostril tubular, dorsally oriented. Posterior nostril slightly closer to eye than to anterior nostril; posterior nostril rim with thin hyaline membrane elevated anteriorly and curving half way around aperture, incomplete posteriorly; aperture ovoid with its long axis oblique to longitudinal body axis. Distance between anterior nostrils smaller than distance between posterior nostrils. Anterior cranial fontanelle tapering anteriorly, opened from mesethmoid to frontals, terminating at or slightly anterior to posterior margin of eye. Posterior cranial fontanelle reduced to ovoid or circular foramen at center of supraoccipital. Supraoccipital process strong, wider at its base, reaching and interdigitating with anterior nuchal plate. Very large eye centered laterodorsally, with free orbital rim. Eye ovoid, horizontal diameter greater than interorbital width. Mouth ventral; corner of mouth posterior to maxillary barbel insertion; premaxillary bone with three irregular rows of conical and depressible teeth (Fig. 3) exposed in ventral view. Upper lip expanded and visible ventrally. Fleshy rictal fold in pocket behind corner of mouth below insertion of maxillary barbel.

Cephalic lateral sensory canals thin; cutaneous canal branches dendritic and sometimes anastomosing on sides and top of head and on nuchal area. Lateral line canal complete, straight, terminating half way middle caudal-fin rays. Lateral line canal surrounded by superficial tubular ossicles, with few ventrally-oriented branches. Three anteriormost lateral line ossicles somewhat enlarged and associated with lateral edge of transverse processes of Weberian vertebrae. Dendritic cutaneous canal branches spreading across tympanic area.

Dentary with three rows of teeth near symphysis narrowing posteriorly to two rows. No teeth present on metapterygoid.

Three pairs of barbels. Maxillary barbel inserted close to anterior nostril and reaching beyond caudal-fin base. All mental barbels inserted at same level and approximately halfway distance from mandibular simphysis to gular fold apex. Inner mental barbel almost reaching insertion of pelvic fin. Tip of outer mental barbel reaching beyond insertion of anal fin.

Gill membranes free supported by 8-9 branchiostegal rays. Gill rakers well-ossified, sharp and slender: 28-33 (n=3).

Dorsal fin with eight dorsal-fin lepidotrichia: spinelet, spine, and six soft, branched rays. Dorsal spine straight, slender, without anterior dentations or anterior distal serrae, and bearing small terminal filament. Dorsal spine plus its own terminal filament about same size as first branched ray. Posterior margin of dorsal spine with sparse, small, sharp, and retrorse or erect dentations. Adipose fin long, inserted close to last dorsal-fin ray; its profile convex; its base length $35.8-39.0 \%$ of SL.

Pectoral fin with one spine and nine branched rays; first soft ray slightly longer than pectoral spine. Pectoral spine strong, sharp; posterior margin with numerous retrorse dentations regularly spaced; anterior margin with weak or no distal serrae but small antrorse dentations along middle third of spine. Posterior cleithral process triangular, short and sharply pointed. About 1/3 length of depressed pectoral spine.

Pelvic fin with six rays, first simple, second longest; inserted below penultimate dorsal-fin ray. Pelvic-fin margin gently convex nearly truncate. Extension of anterior medial process of basipterygium is approximately at same level as anterior lateral process. 
Anal fin concave with nine branched and three simple rays; first and second branched rays more elongate with external tips expanded, forming well developed lobe. Last two anal-fin rays joined, articulating with single expanded pterygiophore.

Caudal fin deeply forked with slender, pointed lobes; without filament on tip of lobes; upper caudal-fin lobe usually longer. Fifteen branched caudal-fin rays. Total vertebrae 4344. First pair of ribs on sixth vertebra.

Urogenital papilla located in shallow depression immediately behind anus between pelvic fins about midway along length of inner fin rays. No apparent sex dimorphism. Distance from anus to anal-fin origin longer than caudal peduncle.

Color in alcohol. Body color light brownish to grey. White, unpigmented stripe ventral to lateral line. Nuchal plates covered with melanophores. Black spot on middle nuchal plate, extending onto base of dorsal-fin spinelet; adjacent nuchal plates also pigmented but not as dark. Dorsal fin with black coloration extending along four anteriormost branched rays, becoming more conspicuous on interradial membranes. Coloration extends up about halfway on first two rays, and fades gradually until fourth ray. Pectoral, adipose, anal, pelvic, and caudal fins hyaline.

Distribution. This species is known only from the middle rio Araguaia. These specimens were collected in Barra do Garças, Mato Grosso State, Brazil (Fig. 4).

Etymology. The specific name (a noun in the genitive case) refers to the rio Araguaia (old spelling Araguaya).

Discussion. The presence of a robust palatine with a crest in the ectopterygoid joint, a synapomorphy for the genus Propimelodus, strongly suggests a close relationship of $P$. araguayae with P. eigenmanni and P. caesius (Fig. 5), all showing the same condition of the ectopterygoid and endopterygoid

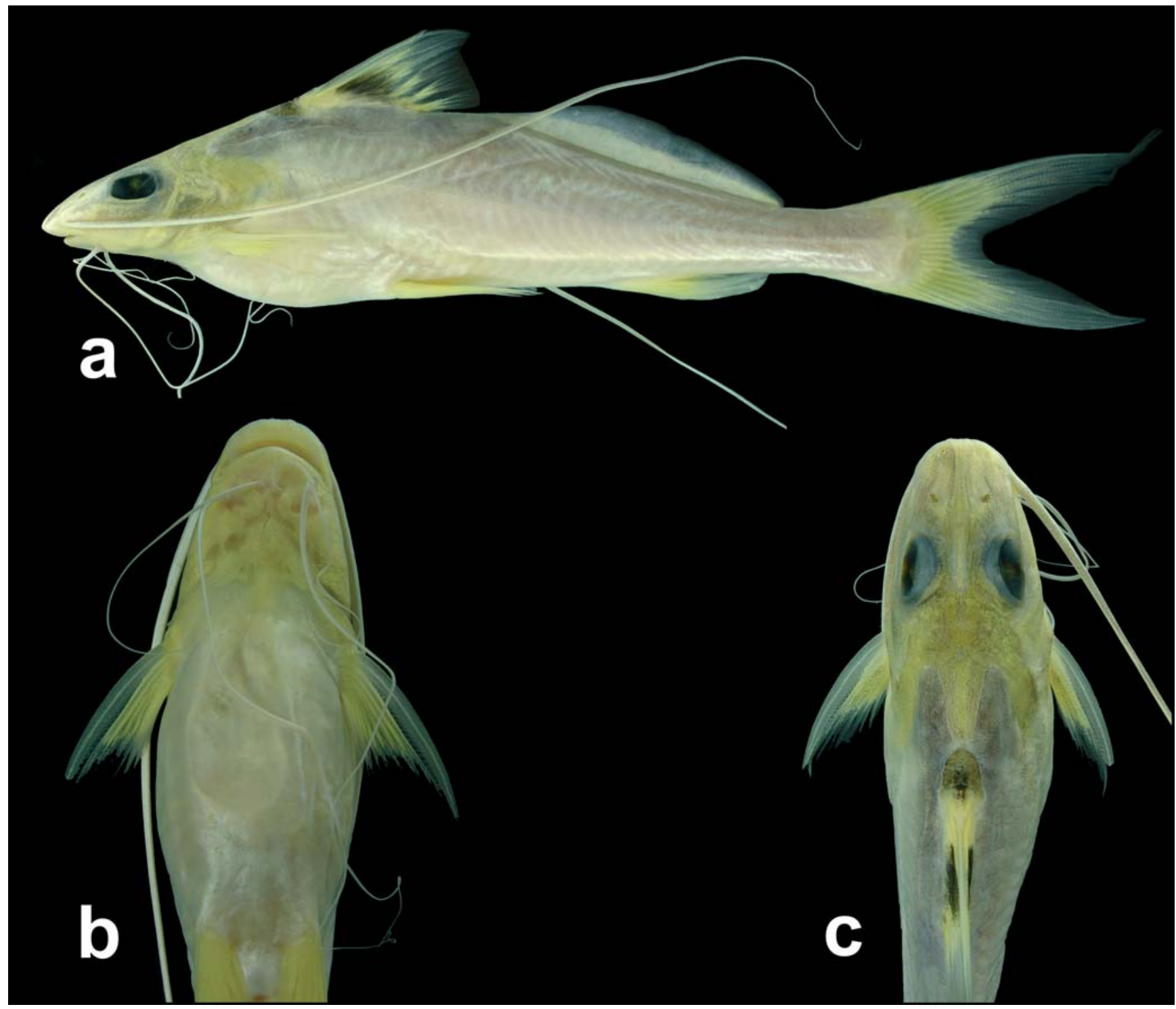

Fig. 1. Propimelodus araguayae, INPA 26119, holotype, $127.1 \mathrm{~mm} \mathrm{SL}$. a, lateral view; b, ventral view of head; c, dorsal view of head. Photographs by F. P. Mendonça. 


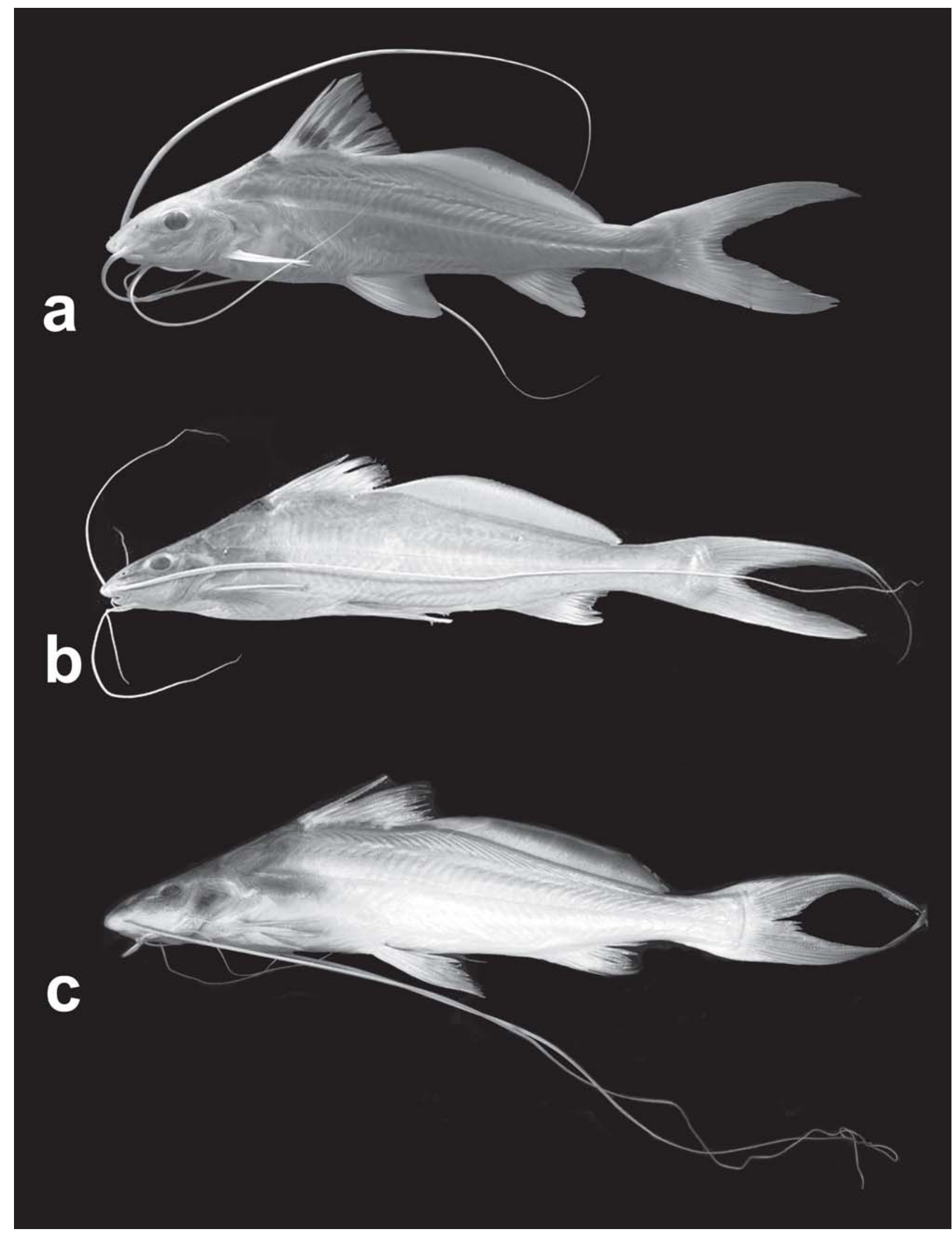

Fig. 2. a, Propimelodus araguayae, INPA 26121, paratype, $130.6 \mathrm{~mm} \mathrm{SL}$; b, P. caesius, MZUSP 88582, holotype; c, P. eigenmanni, FMNH 110975. Photos of $P$. caesius from Parisi et al. 2006 and P. eigenmanni from Lundberg \& Parisi, 2002. Photo of $P$. araguayae by L. M. Sousa. 
Table 1. Morphometric data of Propimelodus araguayae. $\mathrm{SD}=$ standard deviations.

\begin{tabular}{lccccc}
\hline & & \multicolumn{4}{c}{ Paratypes (13) } \\
\cline { 3 - 6 } Measurement & Holotype & Mean & Range & SD \\
\hline Standard length (mm) & 127.1 & 125.8 & 114.1 & 136.9 & 6.3 \\
& Percents of standard length & & & \\
Preadipose length & 52.8 & 51.1 & 49.4 & 54.0 & 1.3 \\
Predorsal length & 32.1 & 31.9 & 31.1 & 32.7 & 0.6 \\
Dorsal-fin base length & 13.8 & 14.2 & 13.4 & 15.1 & 0.6 \\
Dorsal-adipose distance & 6.7 & 5.8 & 4.2 & 6.8 & 0.8 \\
Adipose-fin base length & 36.4 & 37.3 & 35.8 & 39.0 & 0.9 \\
Body depth & 20.2 & 19.3 & 16.4 & 21.1 & 1.2 \\
Preanal length & 66.4 & 67.5 & 64.7 & 70.6 & 1.6 \\
Prepelvic length & 41.8 & 41.2 & 39.6 & 42.4 & 0.9 \\
Anal-fin height & 19.2 & 19.2 & 17.8 & 21.5 & 1.1 \\
Pectoral-fin spine length & 16.9 & 16.3 & 16.3 & 19.1 & 5.2 \\
Anal-fin base length & 10.5 & 10.5 & 9.6 & 11.9 & 0.7 \\
Caudal peduncle length & 23.2 & 22.7 & 20.9 & 23.6 & 0.7 \\
Body width & 15.6 & 15.8 & 14.7 & 17.2 & 0.6 \\
Head length & 21.9 & 21.5 & 20.8 & 22.3 & 0.5 \\
& Percents of head length & & & \\
Snout length & 10.2 & 9.9 & 9.4 & 10.7 & 0.3 \\
Posterior nostril-eye distance & 14.8 & 15.8 & 13.7 & 18.7 & 1.5 \\
Eye diameter horizontal & 31.0 & 31.9 & 29.7 & 34.8 & 1.6 \\
Pre-opercular length & 29.3 & 29.0 & 26.7 & 31.9 & 1.5 \\
Internarial length & 18.4 & 20.4 & 17.9 & 22.3 & 1.3 \\
Internarial posterior width & 17.1 & 18.0 & 16.3 & 19.3 & 0.9 \\
Interorbital width & 18.9 & 20.7 & 18.9 & 23.6 & 1.5 \\
Mouth width & 37.4 & 41.1 & 36.6 & 49.6 & 3.3 \\
& Percent of snout length & & & \\
Eye diameter horizontal & 66.4 & 69.1 & 62.7 & 74.7 & 4.3 \\
\hline
\end{tabular}

bones. However, P araguayae is distinguished from its congeners by the features cited in the diagnosis, such as eye size, black dot on dorsal fin and anal-fin lobe (Fig. 2).

The black dorsal-fin spot in $P$. araguayae shows a condition very different from that in $P$. eigenmanni, with a plain dorsal fin, and $P$. caesius, with a darkening on the distal tips of the first dorsal fin-rays (Fig. 2).

The other two described Propimelodus species have an undeveloped anal fin lobe, thus differing from $P$. araguayae that has a well developed lobe, formed by the enlargement of the first two branched anal-fin rays. This developed condition is shared with Exallodontus aguanai. However, Exallodontus has a remarkable dentition, unique among Pimelodidae.

The number of total vertebrae is low in P. araguayae (4344) in comparison to the other described Propimelodus (4546 in $P$. eigenmanni and $47-48$ in $P$. caesius). According to

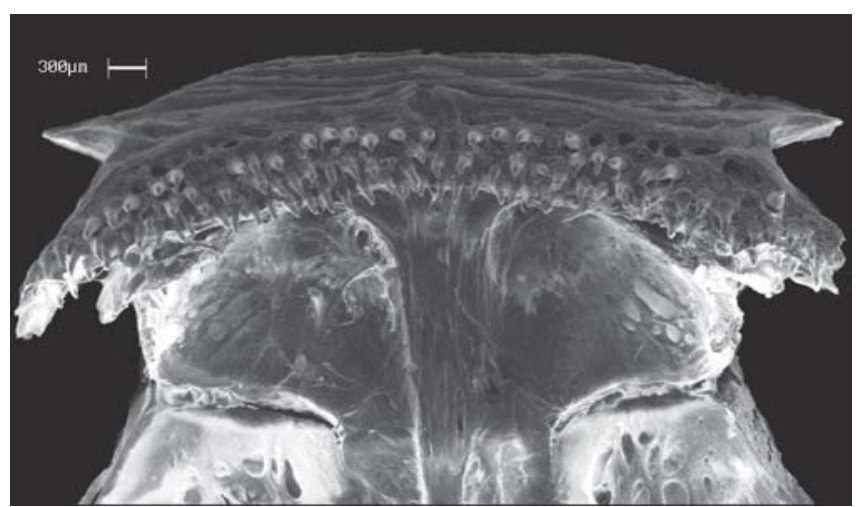

Fig. 3. SEM photograph of premaxilla, ventral view, anterior toward top of page, in Propimelodus araguayae, INPA 26121, paratype.

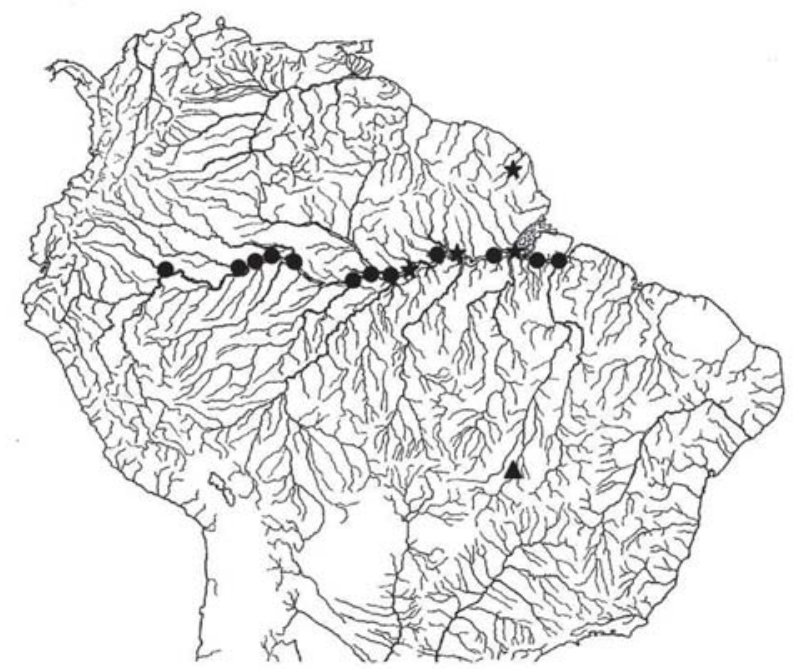

Fig. 4. Partial map of South America showing the distribution localities for Propimelodus araguayae (black triangle), $P$. eigenmanni (black stars) and P. caesius (black circles). Each symbol may represent more than one locality or lot. Localities of $P$. caesius and P. eigenmanni from Parisi et al., 2006 and Lundberg \& Parisi, 2002, respectively.

Lundberg \& Parisi (2002), low vertebral counts can be found in species of the "Pimelodus-group" Pimelodus, Iheringichthys, Parapimelodus, and Duopalatinus peruanus.

Propimelodus araguayae also shares with its congeners an elongated pelvic symphysis developed between expanded membranous bone medial to the anterior limbs of the basipterygium. According to Parisi et al. (2006) these feature also occurs in Exallodontus, Pimelodus altissimus, Duopalatinus peruanus, Cheirocerus, and most members of the Calophysus-group (Calophysus, Luciopimelodus, Pinirampus, Pimelodina). However, in P. araguayae, the extension of the anterior medial process of the basipterygium is approximately at the same level as the anterior lateral process while in $P$. eigenmanni and $P$. caesius the anterior medial process surpasses the anterior lateral process (Fig. 6).

Parisi et al. (2006) located additional feature shared by $P$. caesius, $P$. eigenmanni, and $P$. altissimus, that is the lateral margins of the posterior and middle nuchal plates, and the dorsal margin of the posterior cleithral process sharply jagged or serrated. However this condition was not found in Propimelodus araguayae.

The presence of nearly vertical neural spines of the pos-

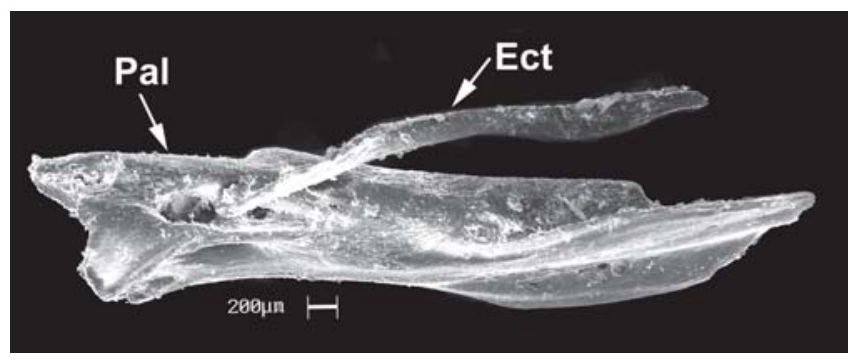

Fig. 5. SEM photograph of palatine and ectopterygoid bones, anterior toward top of page, in Propimelodus araguayae, INPA 26121, paratype. pal, palatine; ect, ectopterygoid. 


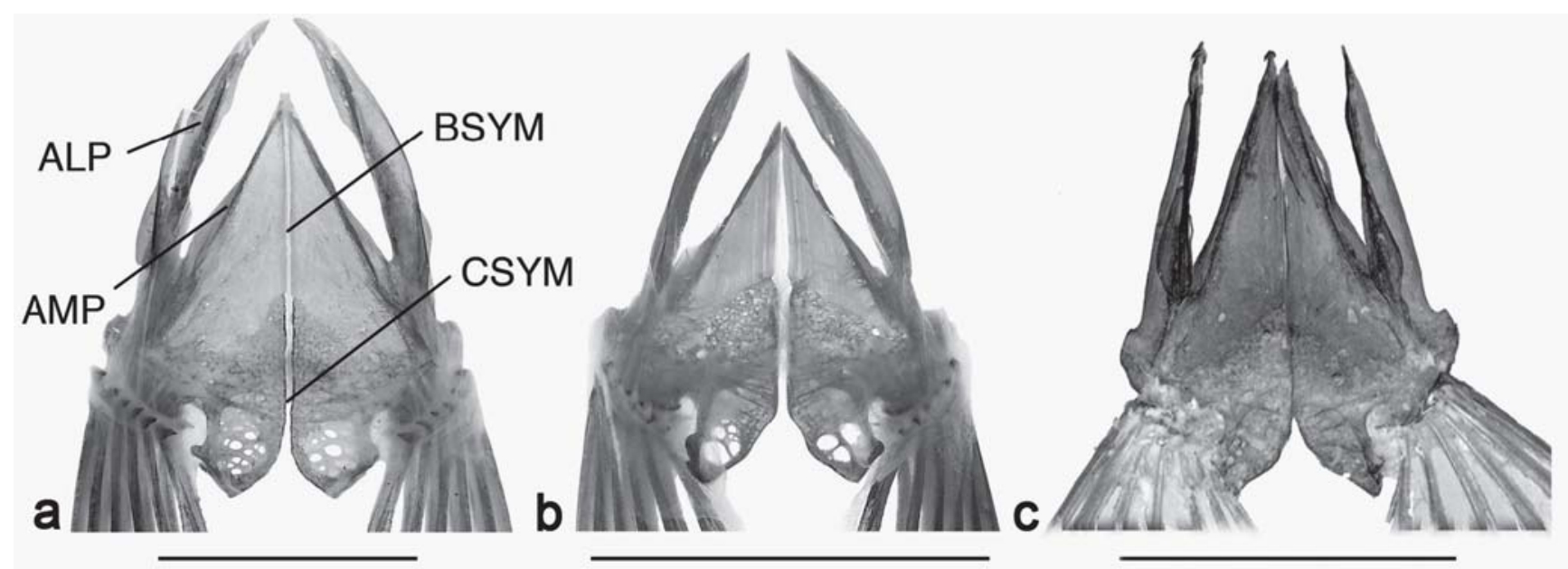

Fig. 6. Basipterygia bones of: a, Propimelodus caesius, ANSP 182256; b, Propimelodus eigenmanni, ANSP 178505; c, Propimelodus araguayae, INPA 26121. Scale bar $=10 \mathrm{~mm}$. ALP $=$ anterior lateral process, AMP = anterior medial process, $\mathrm{BSYM}=\mathrm{membrane}$ bone symphysis, CSYM = synchondral symphysis. Pictures of P. eigenmanni and P. caesius from Parisi et al., 2006.

terior precaudal and anterior caudal vertebrae with distally expanded tips was also observed in Propimelodus araguayae, a condition found in Propimelodus eigenmanni, Exallodontus aguanai (Lundberg \& Parisi, 2002) and Pimelodus altissimus.

This new species is presently known only from the middle part of the rio Araguaia, Mato Grosso State (Fig. 4). Propimelodus eigenmanni and $P$. caesius are commonly found in white, sediment-rich waters and have never been found in the rio Araguaia.

Since its discovery in river channels, Propimelodus species was thought to be restricted to this peculiar environment and it has been usually captured with bottom trawl nets. However, the Araguaia species was captured by hook and line, at the banks of the rio Araguaia, near marginal macrophytes. This species is abundant in the middle course of the rio Araguaia, near Barra do Garças, the type locality, and it is used as food by local people.

Propimelodus eigenmanni is distributed in the Amazon drainage, between the lower rio Madeira and Belém (Fig. 4), as well as in some Guyana rivers. Propimelodus caesius has the largest range of distribution of the genus, and has been collected from Peru to Belém in the Amazon mainstrem and the lower reaches of its principal tributaries.

It seems that $P$. araguayae might be endemic to the rio Araguaia. The intensive collecting effort of the Calhamazon Project (1993-1996) did not report this species in the large rivers of the Amazon. Recent expeditions on the middle to lower course of the rio Araguaia did not produce any Propimelodus araguayae, indicating a possible restricted distribution above the rio das Mortes mouth, in the middle course of Araguaia.

\section{Acknowledgments}

We are very grateful to Jason L. de Oliveira and Humberto P. Rego for help in collecting; Paulo C. Venere (UFMT-ICLMA) for technical support and for donating important specimens; Leandro M. Sousa (MZUSP) and Fernando P. Mendonça (INPA) for the images of preserved material; André C. Canto (INPA) for collection assistance. José W. S. Meirelles from Laboratório Temático de Microscopia Óptica e Eletrônica (INPA) provided the assistance of the SEM images; Alberto Akama, Jeff Podos, and Michael Littmann for critical reading and suggestions; Nelson Papavero for help with the suggestions of scientific name; John Lundberg kindly allowed the publication of the holotypes and pelvic fin photos. This paper was greatly improved by the suggestions of two reviewers. Partial support of publication costs was provided by the All Catfish Species Inventory (NSF DEB 0315963).

Comparative material: Pimelodus altissimus: INPA 8256, 5 (1 cs), (79.8-115.7 mm SL), Brazil, Amazonas, rio Solimões. INPA 8199, 5 (2cs), (76.5-98.7 mm SL), Brazil, Amazonas, Manacapuru, rio Solimões. Exallodontus aguanai: INPA 8988, 7 (2cs), (62.2-107.8 mm SL), Brazil, Amazonas, Manacapuru, rio Solimões. Propimelodus caesius: INPA 26473, 8 (149.7-165 mm SL), Brazil, Amazonas, Manaus, rio Amazonas, costa do Catalão.

\section{Literature Cited}

Lundberg, J. G. \& L. A. McDade. 1986. On the South American catfish Brachyrhamdia imitator Myers (Siluriformes, Pimelodidae), with phylogenetic evidence for a large intrafamilial lineage. Notulae Naturae, 463: 1-24.

Lundberg, J. G. \& B. M. Parisi. 2002. Propimelodus, new genus, and redescription of Pimelodus eigenmanni Van der Stigchel, 1946, a long-recognized yet poorly-known South American catfish (Pimelodidae, Siluriformes). Proceedings of the Academy of Natural Sciences of Philadelphia, 152(1): 75-88.

Parisi, B. M., J. G. Lundberg \& C. Do Nascimiento. 2006. Propimelodus caesius, a new species of long-finned pimelodid catfish (Teleostei: Siluriformes) from the Amazon Basin, South America. Proceedings of the Academy of Natural Sciences of Philadelphia, 155: 67-78.

Potthoff, T. 1984. Clearing and staining techniques. Pp. 35-37. In: Moser, H. G.,W. J. Richards, D. M. Cohen, M. P. Fahay, A. W. Kendall, Jr. \& S. L. Richardson (Eds.). Ontogeny and Systematics of Fishes. Ahlstrom Symposium, American Society of Ichthyologists and Herpetologists, Gainesville. 760p.

Van der Stigchel, J. W. R. 1946. The South American Nematognathi of the Museums at Leiden and Amsterdam. E. J. Brill, Leiden. 204 pp., 3 tabs. [Also published in 1947, Zoologische Mededelingen (Leiden), 27: 1-204.]

Submitted November 2006 Accepted May 2007 